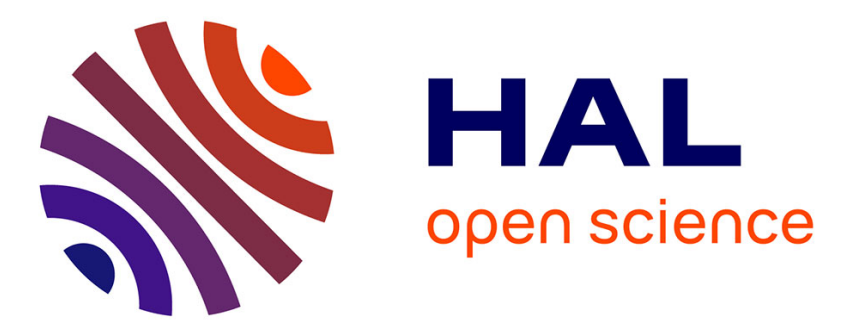

\title{
Evidencing the relationship between isomer spectra and melting: the 20- and 55-atom silver and gold cluster cases
}

\author{
Mathias Rapacioli, Fernand Spiegelman, Nathalie Tarrat
}

\section{To cite this version:}

Mathias Rapacioli, Fernand Spiegelman, Nathalie Tarrat. Evidencing the relationship between isomer spectra and melting: the 20- and 55-atom silver and gold cluster cases. Physical Chemistry Chemical Physics, 2019, 21 (45), pp.24857-24866. 10.1039/C9CP03897C . hal-02326863

\section{HAL Id: hal-02326863 https://hal.science/hal-02326863}

Submitted on 6 Nov 2020

HAL is a multi-disciplinary open access archive for the deposit and dissemination of scientific research documents, whether they are published or not. The documents may come from teaching and research institutions in France or abroad, or from public or private research centers.
L'archive ouverte pluridisciplinaire HAL, est destinée au dépôt et à la diffusion de documents scientifiques de niveau recherche, publiés ou non, émanant des établissements d'enseignement et de recherche français ou étrangers, des laboratoires publics ou privés. 


\title{
Journal Name
}

\section{ARTICLE TYPE}

Cite this: DOI: $00.0000 / x x x x x x x x x x$

\section{Evidencing the relationship between isomer spectra and melting : the 20 - and 55-atom silver and gold clus- ters cases ${ }^{\dagger}$}

\author{
Mathias Rapacioli, ${ }^{* a}$ Fernand Spiegelman, ${ }^{a}$ and Nathalie Tarrat ${ }^{* b}$
}

Received Date

Accepted Date

DOI: $00.0000 / x x x x x x x x x x$

\begin{abstract}
The present work highlights the links between melting properties and structural excitation spectra of small gold and silver clusters. The heat capacity curves are computed for $\mathrm{Ag}_{20}, \mathrm{Au}_{20}$, $\mathrm{Ag}_{55}, \mathrm{Au}_{55}$ and their ions, using a Parallel-Tempering Molecular Dynamics scheme to explore the Density Functional based Tight Binding (DFTB) potential energy surfaces and the multiple histogram method. It is found that clusters having very symmetric lowest energy structures $\left(\mathrm{Au}_{20}\right.$, $\mathrm{Ag}_{55}$ and their ions) present sharp or relatively sharp solid-to-liquid transitions and large melting temperatures, important structural excitation energies and a discrete isomer spectrum. Opposite trends are observed for less ordered clusters $\left(\mathrm{Ag}_{20}, \mathrm{Au}_{55}\right.$ and their ions). Regarding the structural evolution with temperature, very symmetric clusters encounter minor evolution up to the starting melting temperature. The present study also highlights that, in contrast with the case of $A_{20}$, a single electron excess or default is not determinant regarding the melting characteristics, even quantitatively, for clusters containing 55 atoms, for gold as for silver.
\end{abstract}

\section{Introduction}

One of the originalities of clusters, as finite systems, is their melting behaviour. Early studies evidenced the size evolution of the solid to liquid melting and showed that the melting temperature decreases with size in the nanoparticle regime ${ }^{1,2}$. Moreover, while in macroscopic bulk, transitions are sharp and occur at a well defined temperature, phase transitions in finite systems occur over a finite range of temperatures. These mechanisms of phase transitions in clusters were investigated some years ago by several authors ${ }^{3-5}$, who demonstrated the inequivalence of the thermodynamical ensembles for finite systems, in analogy with other finite systems such as nuclei and the major role of phase coexistence at the transition. A number of these pioneering studies were conducted using model Lennard-Jones potentials $4,6,7$. In the case of metal clusters, several experimental ${ }^{8-17}$ and theoretical ${ }^{18-33}$ investigations were achieved to evidence the specific features of finite size melting with a description of the interatomic forces more realistic than the simple Lennard-Jones potentials.

\footnotetext{
${ }^{a}$ Laboratoire de Chimie et Physique Quantiques LCPQ/IRSAMC, UMR5626, Université de Toulouse (UPS) and CNRS, 118 Route de Narbonne, F-31062 Toulouse, France. Tel: 3356155 8318; E-mail: mathias.rapacioli@irsamc.ups-tlse.fr

b CEMES, Université de Toulouse, CNRS, 29, rue Jeanne Marvig, 31055 Toulouse, France. Tel: 3356752 4347; E-mail: nathalie.tarrat@cemes.fr

$\dagger$ Electronic Supplementary Information (ESI) available: [Details on the parameterization of the DFTB method for gold and silver]. See DOI: 00.0000/00000000.
}

While a continuous behaviour of their properties can be expected for relatively large sizes and in the nanoparticle size domain ( $\mathrm{N}>100-1000$ depending on the species), a discrete evolution is exhibited for small sizes down to the microcluster domain. Such finite size effects clearly affects the structure and energetics of clusters with the occurrence of the so-called magic numbers. It also affects the thermodynamical properties ${ }^{28,29,34-38}$. The pioneering experimental study on small sodium clusters in the range $\mathrm{N}=20-147$, reported by Haberland et al. ${ }^{8}$, showed particular large melting temperature for specific size around $\mathrm{N}=55$ and $\mathrm{N}=147$, and strong finite size effects were also observed on the latent heats. The underlying mechanisms of phase transitions were unraveled by a number of authors $12,24,25,27,30,31,34,36,38-41$, detailing the melting process in finite systems to initial isomerisation and finally melting as the number of accessible isomers at a given energy/temperature increases yielding a fluctuating state of the system. Thus, the density of isomers becomes a key property in describing melting at the microscopic level. While the equilibrium geometries in themselves are not supposed to influence melting, the potentials energy landscape is obviously determinant. Nevertheless, the gaps between the lowest energy equilibrium geometry and the lowest isomers can be related to the particular stability of the former, e.g its magic character. It has been shown in a number of simulations that clusters with a magic character often present a large gap to isomerisation, and therefore a higher melting temperature with also a sharper peak in the caloric curve than its 
immediate non-magic neighbors ${ }^{8,42}$. Obviously, the magic character of a given size can stem either from geometric stability or electronic stability, as it is the case in metal clusters. Both types of stabilities can also interfere and even combine, like in the specific clusters $\mathrm{Au}_{20}$ (see ${ }^{32}$ and references therein) or $\mathrm{Al}_{32}$ particularly stable and exhibiting sharp caloric curves ${ }^{17,31}$. Not only size but also charge can influence the caloric properties of relatively small metal clusters ${ }^{17,31,32}$, since charge changes the filling of the electronic shells.

We will hereafter focus on gold and silver clusters. Their structural and melting properties have been investigated using various experimental setups $34,40,43,44$ and theoretical approaches $19,20,24-28,28-30,33,35,36,41,45-49$, mostly with empirical potentials. The most stable structures reported for different cluster sizes exhibit either very regular shape (e.g. $\mathrm{Au}_{20}$ or $\mathrm{Ag}_{55}$ ) or amorphous patterns ${ }^{50}$. As an example, it has been reported that $\mathrm{Au}_{55}$ could present cavities below its outer shell ${ }^{33,48,51}$ and a competition between ordered and disordered geometries has been evidenced in the case of $\mathrm{Au}_{147} 33,52$. Beyond the search for the most stable isomer, studies have been conducted to identify structural excited isomers $26,45,47,51$. In small clusters, a premelting involving transition towards these secondary minima has been reported ${ }^{24-26,35,46,49}$. For large clusters, another possible premelting mechanism has been suggested in the literature involving a melting of the cluster shell prior to the the cluster core $19,36,41$. The melting temperature was reported to increase with the metal nanoparticle size for large clusters $27,34,43$, confirming the pioneer observation of Buffat and Borel ${ }^{2}$. For small clusters, the melting temperature evolution with size is non-monotonous ${ }^{36}$ and the addition or removal of an atom can lead to drastic variation of the melting temperature ${ }^{28-30,45}$. Moreover, for such small sizes, the melting temperature may also depend on the charge state ${ }^{32}$.

The present work is devoted to a detailed comparative study of melting between isovalent noble metal gold and silver clusters for the intermediate sizes 20 and 55, which can be considered as the low limit of the transition between clusters and nanoparticles. It extends a previous work restricted to the influence of charge on the melting of $\mathrm{Au}_{20}{ }^{32}$. While isovalent, silver and gold exhibit quite different properties due to the strong relativistic influence in the electronic structure of gold ${ }^{53,54}$. The size choice was made because because $\mathrm{N}=20$ is a double magic number for gold (geometrically a symmetric pyramid associated with a 20 electron closing of its outer electronic shells ${ }^{55}$ ), while $\mathrm{N}=55$ is not magic for gold. In contrast, $\mathrm{Ag}_{55}$ was found in many theoretical studies as an icosahedron with two complete geometrical shells. Note that as far as we are aware of, the only investigations of the caloric curves for gold and silver cluster clusters with size $\mathrm{N}=55$ were done in the framework of EAM potentials ${ }^{26,56}$. We analyze the different thermodynamical behavior of the silver and gold clusters, based on the correlation between the density of isomers, the isomerization gaps and the characteristic of the solid-to-liquid transition. The influence of the charge of the cluster on the density of isomers for such intermediate sizes is also illustrated. The multiple histogram method to obtain the melting curves from DFTB simulations involving Parallel Tempering Molecular Dynamics is now standard and briefly summarized in the section 2. Section 3 presents the caloric curves for $\mathrm{Au}_{20}^{(-, 0,+)}$, $\mathrm{Ag}_{20}^{(-, 0,+)}, \mathrm{Au}_{55}^{(-, 0,+)}$ and $\mathrm{Ag}_{55}^{(-, 0,+)}$ and the discussion about the underlying microscopic aspects of the transitions. Finally a conclusion is given in section 4 .

\section{Computational details}

In the present work, we have used the Density Functional based Tight Binding (DFTB) scheme ${ }^{57,58}$, in its second order formulation (also known as Self-Consistent Charge DFTB ${ }^{59}$ ), to compute the potential energy surfaces for neutral, anionic and cationic gold and silver clusters. In a previous work ${ }^{60,61}$, we adapted (see supplementary materials for more details) existing gold ${ }^{62}$ and silver parameters ${ }^{63}$ and validated their use to properly model these metals from cluster to bulk sizes.

The exploration of the PES has been done using a ParallelTempering Molecular Dynamics (PTMD) scheme ${ }^{64}$, as implemented in the deMonNano code ${ }^{65,66}$. In this scheme, several trajectories are run in parallel in the canonical ensemble at different temperatures. In practice, 60 trajectories were computed, corresponding to 60 temperatures following an exponential distribution between $50 \mathrm{~K}$ and $2000 \mathrm{~K}$. The trajectory time lengths were progressively increased in order to ensure convergence of the heat capacity curves (between 1 and $6 \mathrm{~ns}$ ). The timestep was $1.5 \mathrm{fs}$ and the temperature was controlled by a Nose-Hoover chain 67,68 of 5 thermostats coupled to the system through a frequency of $80 \mathrm{~cm}^{-1}$. In order to increase ergodicity, exchanges of temperatures between the different trajectories were attempted each 1.2 ps using a metropolis criterion.

Although heat capacities can in principle be build from the potential energy distribution obtained for the different simulated temperatures, we have used the multiple histogram approach, as formulated by Labastie and Whetten ${ }^{4}$ which reduces the statistical noise and extrapolates heat capacity values for temperatures not included in the PTMD simulation.

\section{Results and discussion}

The structural aspects for neutral, cationic and anionic $\mathrm{Ag}_{20}$, $\mathrm{Au}_{20}, \mathrm{Ag}_{55}$ and $\mathrm{Au}_{55}$ within the DFTB approach were discussed in details in a previous work ${ }^{51}$ from global exploration (PTMD complemented by quenching). The lowest energy isomers for $\mathrm{Au}_{20}, \mathrm{Au}_{20}^{+}$and $\mathrm{Au}_{20}^{-}$were found to be very symmetric structures, namely a $T_{d}$ pyramid fort the neutral cluster and a $T_{d}$ pyramid with small Jahn-Teller deviations for the anion, in agreement with previous experimental and theoretical works ${ }^{69-71}$. In contrast, the lowest energy structures of $\mathrm{Ag}_{20}$ and its ions are essentially based on pentagonal arrangements and have lower symmetry, namely $C_{3}$ for the neutral and the cation, $C_{S}$ for the anion. For size $\mathrm{N}=55$, the results are interchanged. The lowest energy structures of $\mathrm{Ag}_{55}$ neutral and ions all result from small Jahn-Teller distorsions of the very symmetric $\left(I_{h}\right)$ double icosahedron $\left(D_{2 h}, D_{5 d}\right.$ and $D_{3 d}$ for the neutral, the cation and the anion respectively), while the low energy isomers of $\mathrm{Au}_{55}^{(-, 0,+)}$ have more disordered shapes with cavities inside the cluster. 

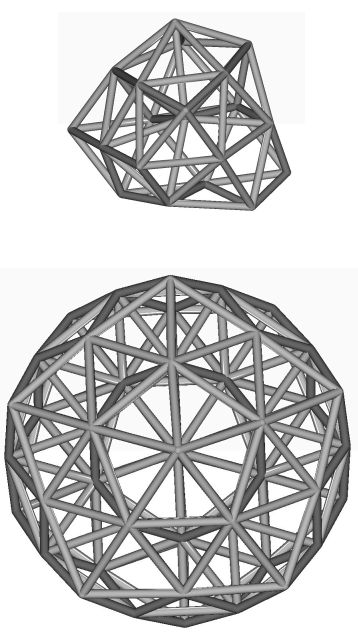
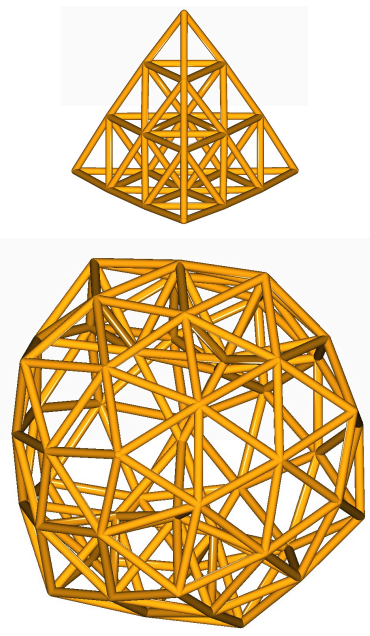

Fig. 1 Structures of the DFTB lowest-energy isomers of $\mathrm{Ag}_{20}, \mathrm{Au}_{20}, \mathrm{Ag}_{55}$ and $\mathrm{Au}_{55}$.

Figure 1 only displays the lowest energy equilibrium structures of the neutral clusters. The equilibrium structures of the charged clusters presenting only small deformations of the neutral ones, the details would not be discernible at the figure scale. For more information, we refer the reader to our previous publication ${ }^{51}$. Note that the presence of cavities in $\mathrm{Au}_{55}$ gold clusters has been recently confirmed by two other DFT studies ${ }^{33,48}$. In itself, the fact that the structures are symmetric or disordered is not directly influential on the thermodynamical properties which result from averages at a given temperature. However, very symmetric structures often correspond to particularly stable equilibrium structures and may therefore be associated with larger structural excitation energies and higher melting temperatures than the disordered ones. The variability of the isomer spectrum is thus determinant on the thermodynamic properties $21,26,45$ and will be analyzed in the discussion.

The heat capacity curves as a function of the canonical temperature are shown in figure 2 in the temperature range of the solid-liquid transition. The case of $\mathrm{Au}_{20}$ was already discussed with respect to charge effects ${ }^{32}$ and is given here for comparison. The first observations concern the temperature widths of the transitions and the heights of the associated peaks. In the case of neutral $\mathrm{Au}_{20}$ and $\mathrm{Ag}_{55}$, the transition is rather well defined, with peak heights around $C / N=8$ and $6 k_{B}$ respectively and with half-widths around $300 \mathrm{~K}$ and $180 \mathrm{~K}$ respectively (taken as the widths at the peaks half heights). The situation is quite different in the case of $\mathrm{Ag}_{20}$ which exhibits an extremely smooth and flat transition and in the case of $\mathrm{Au}_{55}$ for which the width of the transition extends almost over the whole temperature domain investigated with a roughly linear increase, up to the well defined peak maximum. The characteristic temperatures of the heat capacity curves are given in table 1 . The transition temperatures $T_{\text {melt }}$ are taken as the peak maxima. We also give the inflexion temperatures $T_{\text {inflex }}$, which are usually interpreted as the starting melting temperatures. However, in some cases, e.g. $\mathrm{Ag}_{20}$ and $\mathrm{Au}_{55}$, the inflexion points of the caloric curves are uncertain, and we have alternatively defined the starting temperature $T_{\text {start }}$ as the left temperature at half width. The melting temperatures $T_{\text {melt }}$ for neutral $\mathrm{Ag}_{20}, \mathrm{Ag}_{55}, \mathrm{Au}_{20}$ and $\mathrm{Au}_{55}$, are $581 \mathrm{~K}, 763 \mathrm{~K}$, $1101 \mathrm{~K}$ and $1154 \mathrm{~K}$ respectively. One can observe that while the addition or removal of a single electron may quantitatively change the position of the heat capacity peaks (see for instance $\mathrm{Au}_{20}$ and its ions), it does not significantly change the qualitative aspects of the heat capacity curves.

\begin{tabular}{c|c|c|c|} 
& $T_{\text {start }}$ & $T_{\text {inflex }}$ & $T_{\text {melt }}$ \\
\hline \hline $\mathrm{Ag}_{20}^{-}$ & 359 & - & 574 \\
$\mathrm{Ag}_{20}$ & 411 & 418 & 581 \\
$\mathrm{Ag}_{20}^{+}$ & 215 & - & 398 \\
\hline $\mathrm{Au}_{20}^{-}$ & 646 & 691 & 822 \\
$\mathrm{Au}_{20}$ & 978 & 1017 & 1101 \\
$\mathrm{Au}_{20}^{+}$ & 717 & 763 & 867 \\
\hline $\mathrm{Ag}_{55}^{-}$ & 685 & 730 & 795 \\
$\mathrm{Ag}_{55}$ & 672 & 717 & 763 \\
$\mathrm{Ag}_{55}^{+}$ & 665 & 685 & 724 \\
\hline $\mathrm{Au}_{55}^{-}$ & 795 & - & 1115 \\
$\mathrm{Au}_{55}$ & 808 & - & 1154 \\
$\mathrm{Au}_{55}^{+}$ & 678 & - & 1160 \\
\hline \hline
\end{tabular}

Table 1 Starting melting temperatures $T_{\text {start }}$, inflexion point temperatures $T_{\text {inflex }}$ and melting temperatures $T_{\text {melt }}$ in $\mathrm{K}( \pm 3 \mathrm{~K})$ for $\mathrm{Ag}_{20}^{(-, 0,+)}, \mathrm{Au}_{20}^{(-, 0,+)}$, $\mathrm{Ag}_{55}^{(-, 0,+)}$ and $\mathrm{Au}_{55}^{(-, 0,+)}$.

In a previous references 32,51 , the structural excitation energies of all isomers found below $1 \mathrm{eV}$ within the PTMD /quenching exploration scheme were reported. Important energy gaps between the lowest energy isomers and the first excited ones were found in the case of the symmetric clusters, namely $\mathrm{Au}_{20}$ and $\mathrm{Ag}_{55}(0.64$ $\mathrm{eV}$ for neutral $\mathrm{Au}_{20}$ and $0.51 \mathrm{eV}$ for $\mathrm{Ag}_{55}$ for instance). Conversely, in the less ordered systems $\mathrm{Ag}_{20}$ and $\mathrm{Au}_{55}$, small gaps were found ( $0.12 \mathrm{eV}$ for $\mathrm{Ag}_{20}$, almost no gap in the case of $\mathrm{Au}_{55}$ ). This fingerprints could still be observed in the ions, with finite well established gaps (somewhat reduced) in $\mathrm{Au}_{20}^{(-,+)}$and $\mathrm{Ag}_{55}^{(-,+)}$and very small or vanishing gaps in $\mathrm{Ag}_{20}^{(-,+)}$and $\mathrm{Au}_{55}^{(-,+)}$. More thorough insight can be reached from the features of the global isomer spectra given in figure 3. One can observe that the sharpest transitions, corresponding to the most ordered clusters $\mathrm{Au}_{20}$ and $\mathrm{Ag}_{55}$ are related to cases where there is a significant isomer gap between the lowest energy structure and the higher ones. Let us note that in the case of $\mathrm{Au}_{20}$, the isomer spectrum shows several isomers lying at extremely low energies close to that of the best structure, which are isomers corresponding to slight Jahn-Teller distortions of the symmetric $T_{d}$ structure. Since the present work does not include quantum effect nor vibrational zero point energy effects, we do not discuss those isomers which moreover do not bring any visible features in the heat capacity curve at low temperature. As mentioned above, the gaps are particularly large for $\mathrm{Au}_{20}$ and $\mathrm{Ag}_{55}$, and the isomer spectrum keeps a discrete nature up to $1 \mathrm{eV}$. This is at strong contrast with $\mathrm{Ag}_{20}$ for which the isomer spectrum still exhibits lines corresponding to various isomers, however lying close-by. In $\mathrm{Au}_{55}$, the isomer spectrum is so congested that it appears as a quasi continuum above $0.15 \mathrm{eV}$. These high densities of low-energy isomers are associated with flat or 

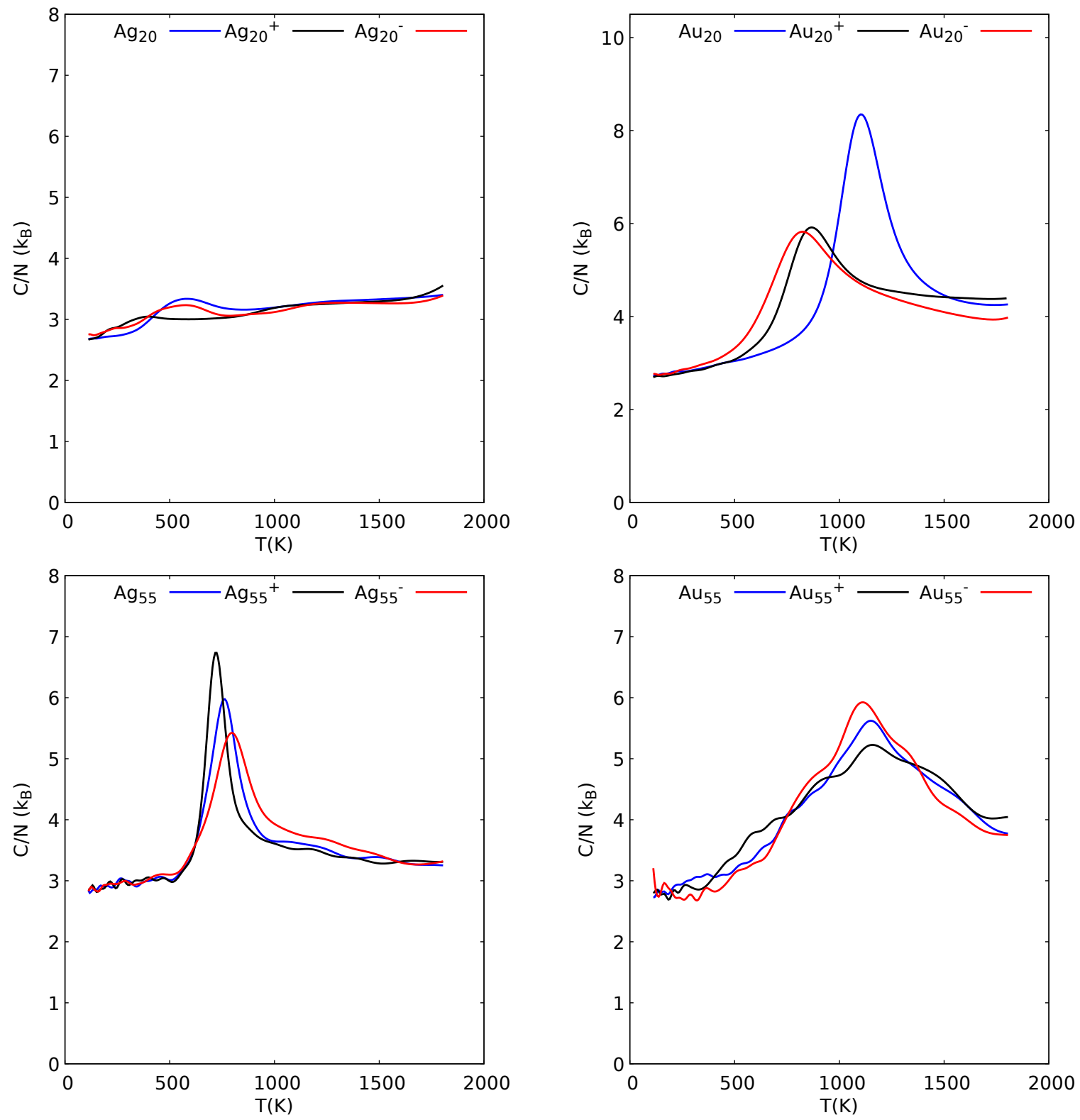

Fig. 2 Canonical heat capacity curves per atom $\left(\mathrm{C} / \mathrm{N}\right.$ in $\left.\mathrm{k}_{B}\right)$ for neutral (blue), cationic (black) and anionic ( $\left.\mathrm{red}\right) \mathrm{Ag}_{20}, \mathrm{Au}_{20}, \mathrm{Ag}_{55}$ and $\mathrm{Au}_{55}$ clusters. 
very broad transition features. Several oscillations appear in the raise of the caloric curve. We checked that the visited structures do not include a few specific isomers only but a large number of noticeably different amorphous structures, consistently with the almost continuous isomer spectrum. It is thus not possible to assign those features to uniquely defined isomerization. We now consider the ions. In the case of $\mathrm{Au}_{20}^{-}$and $\mathrm{Au}_{20}^{+}$, the gaps are reduced to $0.35 \mathrm{eV}$ and $0.27 \mathrm{eV}$ respectively, and a larger number of isomers appear in the range 0.3-1 eV. This provides an explanation for a broadening of the transition peak and a shift of the melting to lower temperatures, namely 822 and $867 \mathrm{~K}$ respectively. $\mathrm{Ag}_{55}$ is a larger cluster in which the addition or the removal of an electron is less influential. Its isomer spectrum is not significantly changed, characterized by first structural excitation gaps of 0.45 , 0.46 and $0.46 \mathrm{eV}$ for the neutral, the anion and the cation respectively. The isomer gap in $\mathrm{Ag}_{20}^{+}$is about the same as that of the neutral, while its isomer spectrum becomes strongly congested in the range $0.18-0.38 \mathrm{eV}$, which may explain the almost flat aspect of its heat capacity curve, the melting temperature indicated in table 1 being to be taken with extreme caution. In $\mathrm{Ag}_{20}^{-}$, the first structural energy gap is strongly reduced and a very smooth heat capacity is obtained with two shoulders. The isomer spectrum of $\mathrm{Au}_{55}^{-}$is even more congested than the spectrum of the corresponding neutral cluster. Concerning $\mathrm{Au}_{55}^{+}$, a lower density of isomers is observed between 0.1 and $0.3 \mathrm{eV}$. Finally, an important observation is that, while in $\mathrm{Au}_{20}$ and $\mathrm{Ag}_{20}$ the effect of a single charge on the melting temperature may result in shifts in the range 200$300 \mathrm{~K}$, this effect almost vanishes for the largest clusters $\mathrm{Au}_{55}$ and $\mathrm{Ag}_{55}$ where the shifts are only in the range 30-50 K.

In order to get further insight in the structural order changes along the melting process, we have also analyzed the cluster structures by computing the averaged Radial Distribution functions (RDF) at a given temperature defined as

$$
g_{0}(r, T)=<\frac{1}{N} \sum_{i}^{N} \frac{1}{\sqrt{2 \pi} \sigma} e^{-\frac{\left(r_{0 i}-r\right)^{2}}{2 \sigma^{2}}}>_{T}
$$

where index 0 stands for the center of mass of the cluster and $i$ a current atom. The average concerns all the cluster configurations at a given temperature. The gaussian smoothing was used ( $\sigma=0.05 \AA$ ) to reduce the noise, especially at low temperature. Temperature-dependent RDFs are reported in Fig. 4 for $\mathrm{Ag}_{20}^{(-, 0,+)}$ and $\mathrm{Au}_{20}^{(-, 0,+)}$, and in Fig. 5 for $\mathrm{Ag}_{55}^{(-, 0,+)}$ and $\mathrm{Au}_{55}^{(-, 0,+)}$. On these figures, the RDF at the melting temperature $T_{\text {melt }}$ is depicted as solid black lines and the one at $T_{\text {start }}$ as dashed black lines. Clearly, due to their high symmetry, the RDF of $\mathrm{Au}_{20}$ and $\mathrm{Ag}_{55}$ at low temperature both have only a few characteristic and rather narrow peaks, corresponding respectively to the pyramidal structure and to the icosahedron. Obviously when the temperature increases, the atomic fluctuations induce a broadening of the RDF peaks. One can observe on the $\mathrm{Au}_{20}$ spectrum that the evolution of the RDF between $T_{\text {start }}$ and $T_{\text {melt }}$ is quite significant. At $T_{\text {start }}$, the peak structure in the RDF is still clearly identifiable and still associated to a given structure perturbed by vibrational fluctuations. Alternatively, at the meting temperature, even though the RDF is not flat, the peaks at 1.8 and $4.8 \AA$ have almost disappeared and the RDF has almost completely lost its structuration. A similar situation can be observed in $\mathrm{Ag}_{55}$, except that the two-shell structure seems to be still preserved within the two-maxima feature of the RDF around 2.8 and $4.9 \AA$ A. Let us note that, above the melting temperature, some distances are now recorded between the two shells in the range 3-4 $\AA$, fingerprinting exchanges between the shells. Again, the situation is significantly different in the case of $\mathrm{Ag}_{20}$ and $\mathrm{Au}_{55}$. In $\mathrm{Ag}_{20}$, the peak structure is still slightly visible, however considerably smeared. In $\mathrm{Au}_{55}$, the RDF at $T_{\text {start }}$ has lost its initial structure, the two peaks of the RDF at 4.8 and $5.4 \AA$ being merged. Moreover, there is no strong difference between the RDFs at $T_{\text {start }}$ and $T_{\text {melt }}$, which is clearly related to the temperature width and the smoothness of transition for these clusters. The same differential behaviour of the RDF is seen for the ions $A u_{20}^{(-,+)}$and $A g_{55}^{(-,+)}$on one side (sharp transition), $A g_{20}^{(-,+)}$and $A u_{55}^{(-,+)}$on the other side (smooth transition). From the above analysis, it appears that the melting temperature can be inferred from the RDF evolution in the case of ordered clusters such as $\mathrm{Au}_{20}$ and $\mathrm{Ag}_{55}$, while the continuous evolution of the RDF in disordered cases prevents such determination.

A number of previous theoretical studies have determined the caloric curve of gold and silver clusters (mainly neutrals), either for small sizes or in the nanoparticle regime up to a few thousands of atoms 19,20,24-28,28-30,33,35,36,41,45-47,49. First-principles calculations were used to investigate the thermal properties of small gold clusters up to $\mathrm{N} \approx 24^{28,29,45,47}$, with a special focus on $\mathrm{Au}_{20}$ and its neighbours. The thermal stability of small gold cages was examined by Chandrachud et al. ${ }^{45}$. Most of the other studies were conducted using EAM-type potentials. In large clusters and nanoparticles, emphasis was put on the occurrence of a surface premelting $19,36,41,49$. In gold, specific studies were concerned with a solid-to-solid transformation into metastable icosahedral shape ${ }^{35,46}$.

Mainly two studies, both using EAM-type potentials, have investigated the melting of gold and silver clusters for size $\mathrm{N}=55$. Hamid et al. conducted an EAM-type study on several metal clusters emphasizing the crossover between icosahedral $I_{h}$ and $f c c O_{h}$ morphologies and determined the caloric curves ${ }^{56}$. For $\mathrm{Au}_{55}$, they found a melting temperature close to $400 \mathrm{~K}$, quite far from the one determined in the present study $\left(T_{\text {melt }}=1154 \mathrm{~K}\right)$. For reference, the bulk melting temperature of gold is $1337 \mathrm{~K}^{72}$. It is to be noticed that neither the $I_{h}$ nor the $O_{h}$ structures are the lowest energy structures, neither in the EAM study of Hamid et al. nor in the present study. Finally, let us mention that the melting temperature of $\mathrm{Au}_{20}$ in the present DFTB approach is $1101 \mathrm{~K}$ to be compared with $770 \mathrm{~K}$ in the DFT/LDA study of Krishnamurty et al. ${ }^{29}$. This was discussed in a previous article ${ }^{32}$ as related to different isomer gaps (0.64 eV with DFTB, 0.75 with DFT/TPSS ${ }^{71}$ and 0.44 with $\mathrm{DFT} / \mathrm{LDA}^{29}$ ).

In the case of $\mathrm{Ag}_{55}$, Mottet et al. ${ }^{26}$ found a melting at $570 \mathrm{~K}$, starting from $530 \mathrm{~K}$. Both this latter result and our present melting temperature $\left(T_{\text {melt }}=763 \mathrm{~K}\right)$ are significantly lower than that of the bulk $\left(1232 \mathrm{~K}^{73}\right)$. In the two studies, the first isomerisation gaps are similar $(\approx 0.5 \mathrm{eV})$, showing that the first gap is not 

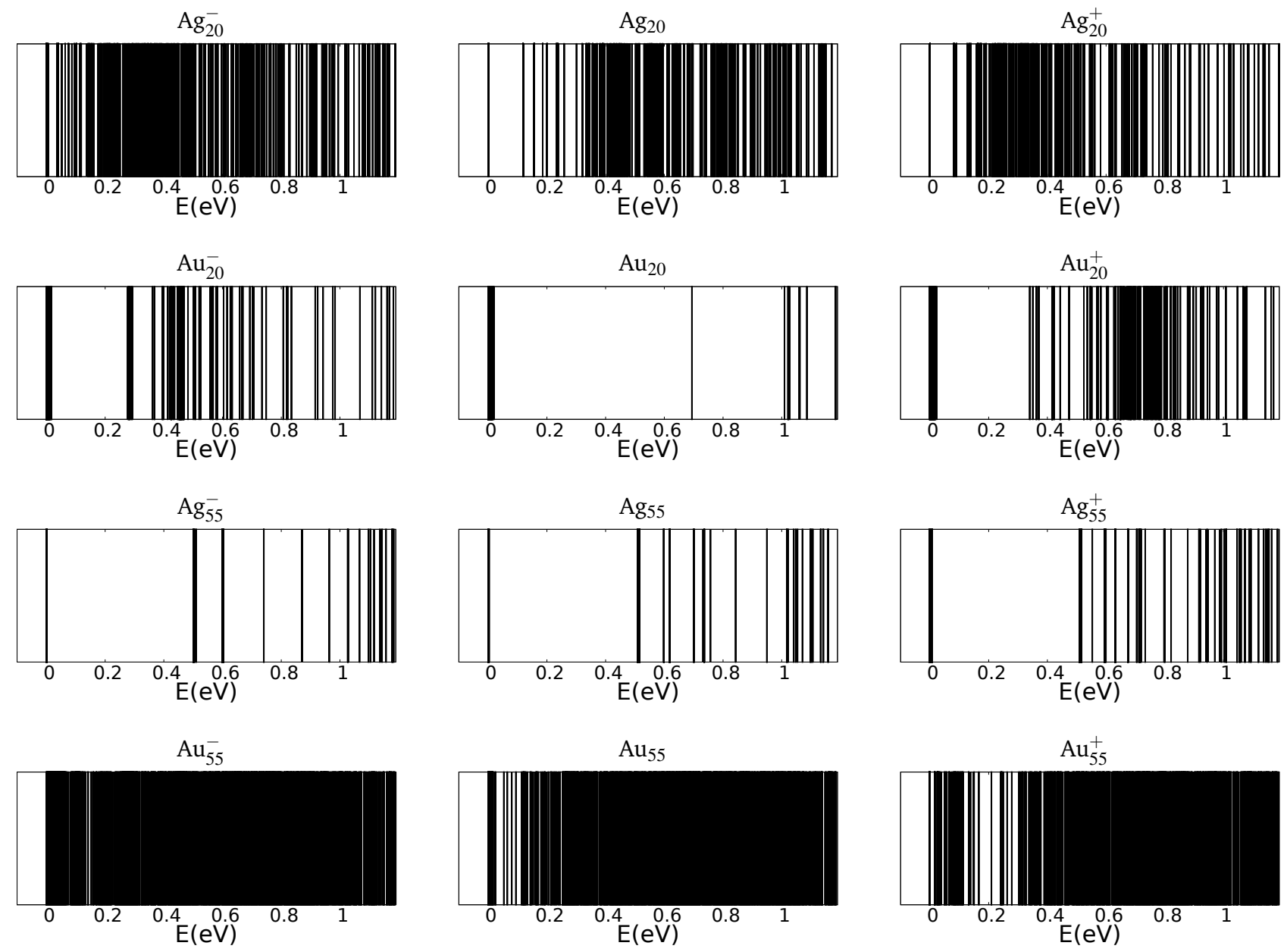

Fig. 3 Structural excitation energies of minimized structures for $\mathrm{Ag}_{20}^{(-, 0,+)}, \mathrm{Au}_{20}^{(-, 0,+)}, \mathrm{Ag}_{55}^{(-, 0,+)}$ and $\mathrm{Au}_{55}^{(-, 0,+)}$. 

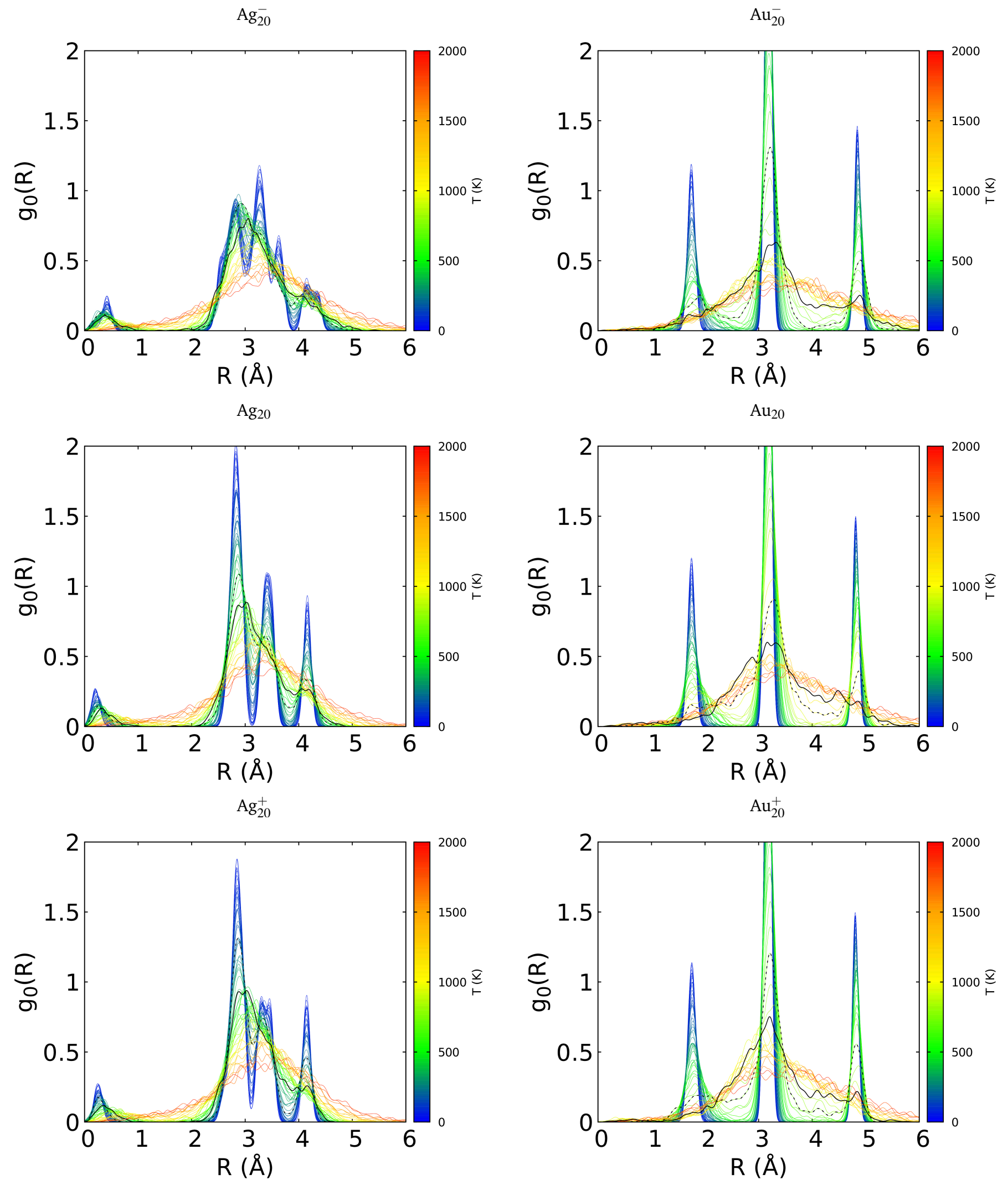

Fig. 4 Temperature-dependent Radial Distribution Functions for $\mathrm{Ag}_{20}^{(-, 0,+)}$ and $\mathrm{Au}_{20}^{(-, 0,+)}$. The temperature color code is indicated on the right. $\mathrm{RDF}$ at $T_{\text {start }}$ : dashed black line. RDF at $T_{\text {melt }}$ : solid black line. 


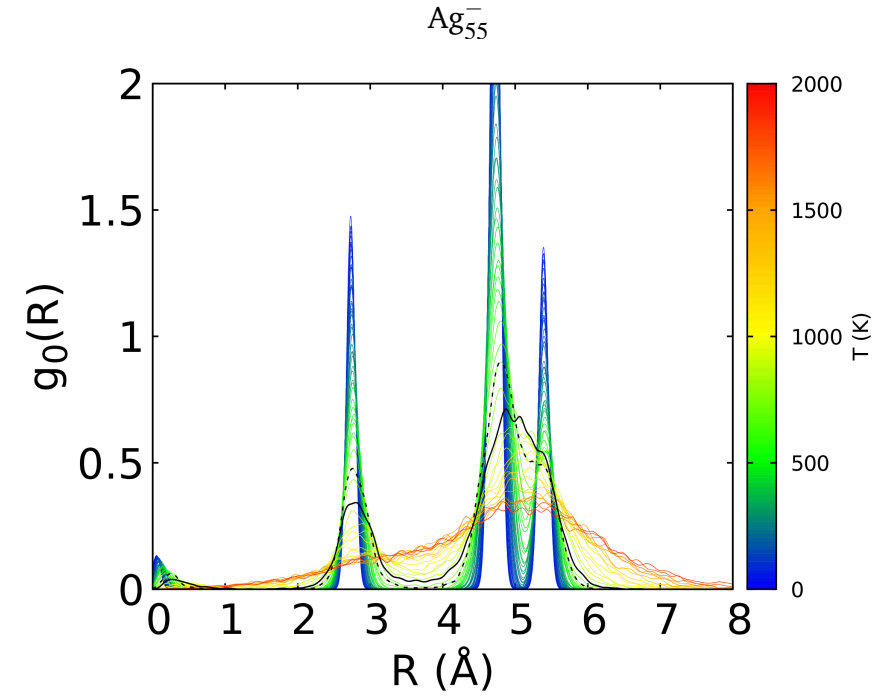

$\mathrm{Ag}_{55}$

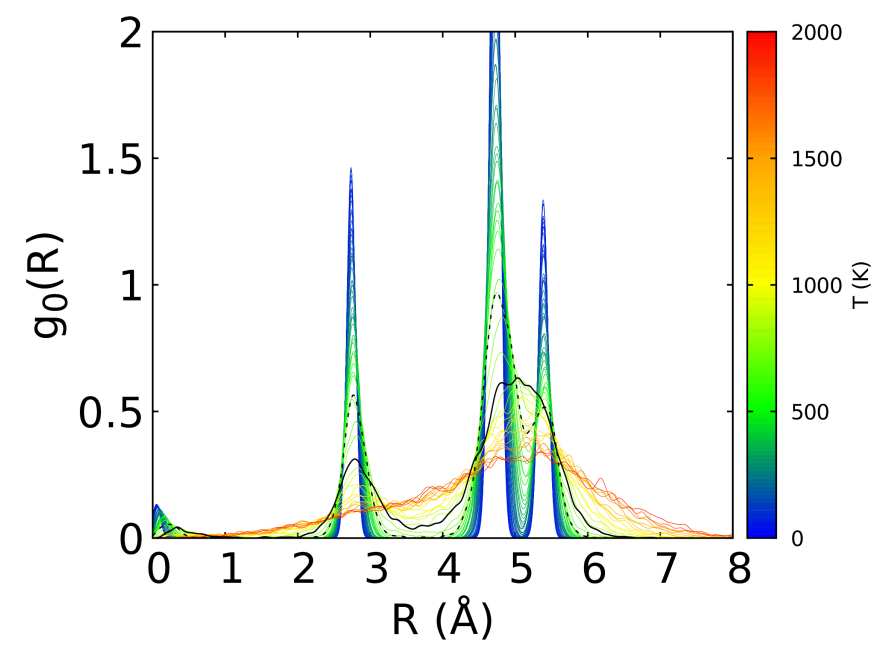

$\mathrm{Ag}_{55}^{+}$

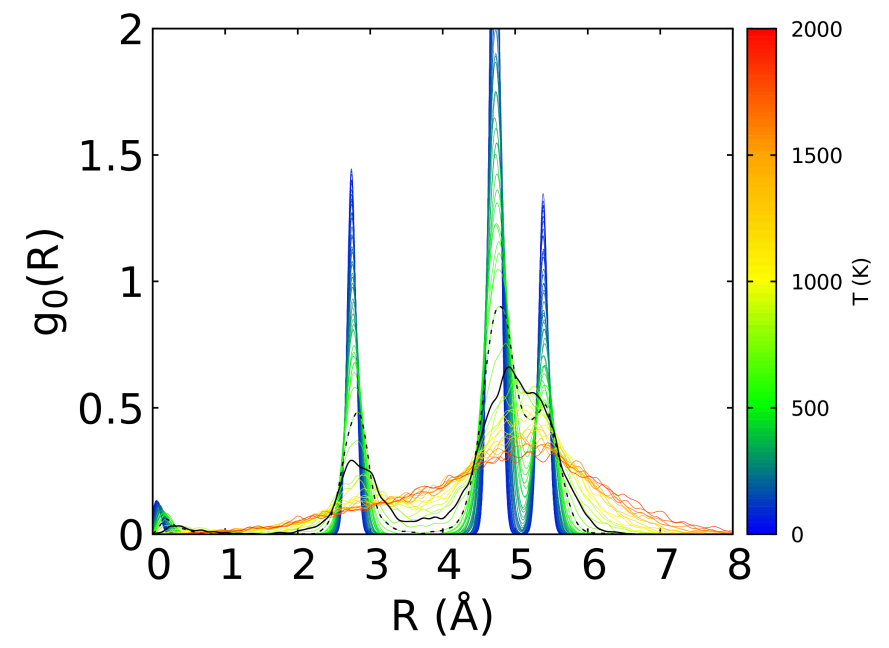

$\mathrm{Au}_{55}^{-}$

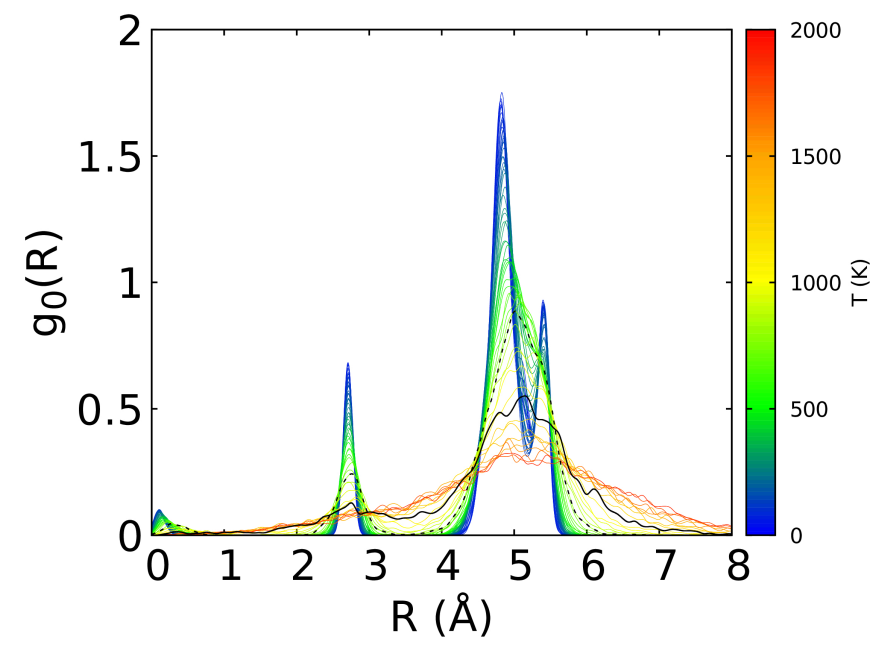

$\mathrm{Au}_{55}$

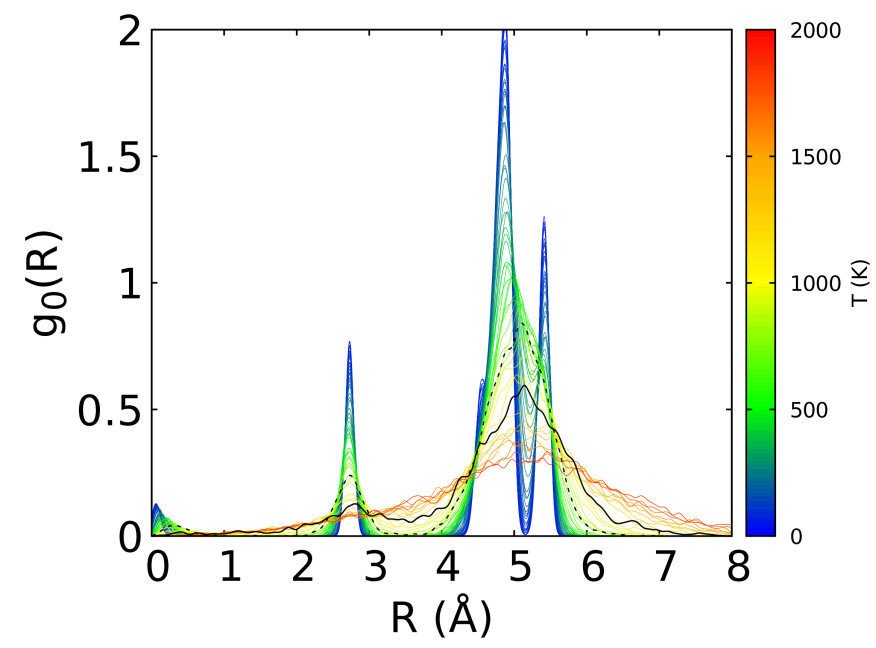

$\mathrm{Au}_{55}^{+}$

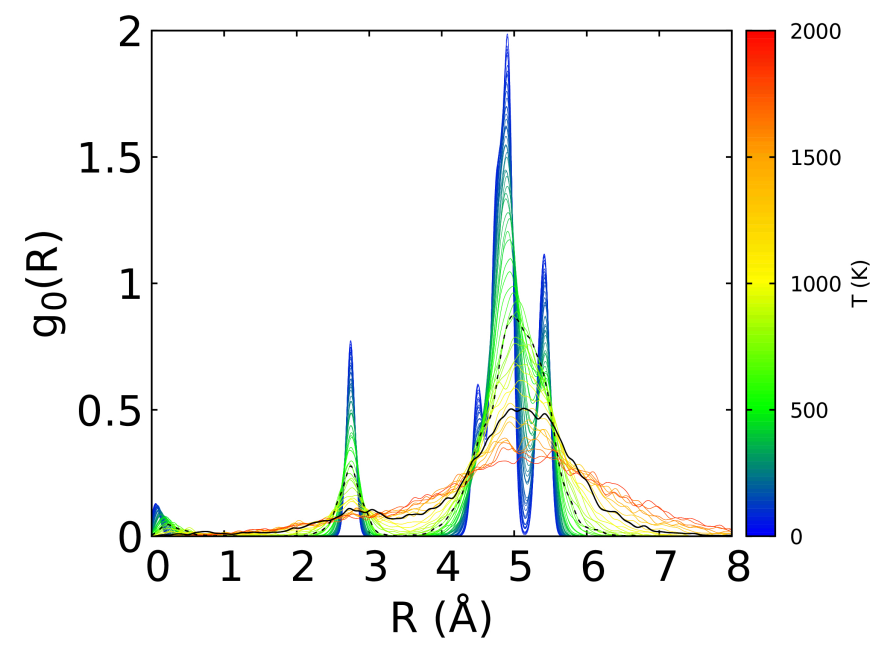

Fig. 5 Temperature-dependent Radial Distribution Functions for $\mathrm{Ag}_{55}^{(-, 0,+)}$ and $\mathrm{Au}_{55}^{(-, 0,+)}$. The temperature color code is indicated on the right. $\mathrm{RDF}$ at $T_{\text {start }}$ : dashed black line. RDF at $T_{\text {melt }}:$ solid black line. 
completely sufficient to characterize the transition. Clearly, the differences between the melting temperatures are to be related to the different potentials used and the specific isomer densities above the first gap in the two respective studies.

We have addressed here some specific cases, either ordered clusters presenting a large gap between a single lowest isomer and the next one, or disordered clusters presenting almost no gap at all. Clearly, other sizes may exhibit a different energy landscape with two or more low energy isomers, where the temperature evolution would start as a structural isomerization to a hot solid prior to melting. In such case, the isomer spectrum would exhibit two or more well identified low energy lines and might induce a shoulder or a peak in the capacity curve below the main one (see for instance the case of $\mathrm{Al}_{115}^{+}{ }^{38}, \mathrm{Ga}_{80}^{+}{ }^{11}$ and previous discussions ${ }^{12,31,38,74}$ ). Let us mention that the identification of a second isolated isomer well separated from the higher ones does not necessarily induce any premelting feature in the caloric curve, as evidenced in the case of $\mathrm{Au}_{20}$ in our previous work ${ }^{32}$.

\section{Conclusion}

We have determined the heat capacity curves for $\mathrm{Ag}_{20}, \mathrm{Au}_{20}$, $\mathrm{Ag}_{55}, \mathrm{Au}_{55}$ and their ions associated with the solid-to-liquid transition. The present work highlights the direct links between the structural excitation spectra and the melting properties of small gold and silver clusters. Clusters exhibiting very symmetric low energy structures, such as $\mathrm{Au}_{20}$ and $\mathrm{Ag}_{55}$ and their ions, display large structural excitation energies and a discrete nature of their isomer spectra below $1 \mathrm{eV}$. They present sharp or relatively sharp solid-to-liquid transitions and rather large melting temperatures, relatively to their respective sizes. A relatively minor evolution of their structure is observed up to the starting melting temperature. Conversely, less ordered clusters, such as $\mathrm{Ag}_{20}, \mathrm{Au}_{55}$ and their ions, have small or vanishing structural energy gaps, isomer spectra almost continuous above low energies and they undergo a much smoother transition. Moreover, the evolution of the $\mathrm{RDF}$ of $\mathrm{Au}_{55}$ shows a loss of structuration significantly below the melting temperatures associated with a transition within a broad temperature range. The identification of these very different structural and thermodynamic characteristics for clusters of similar size composed of the isovalent metals gold and silver completes the picture of dissimilar properties for those two elements. The correlation between the thermodynamical behaviour and the isomer spectrum observed in the present work also gives credit to the description of the onset of disorder at phase changes in the spirit developed in the early works of Rose and Berry ${ }^{75}$ and concerned with the topologies of the energetic and entropic high-dimensional landscapes of clusters and the role of amorphous basins $v s$ ordered configurations. Note that, relatively to our previous work on the influence of the charge on the caloric properties of $\mathrm{Au}_{20}{ }^{32}$, this study also shows that a single electron default or excess is much less determinant, even quantitatively, for size $\mathrm{N}=55$, than for size $\mathrm{N}=20$.

\section{Conflicts of interest}

There are no conflicts to declare.

\section{Acknowledgements}

This work was granted access to the HPC resources of CALMIP (Grants p18009, p0059 and p1303). It was supported by the CNRS-GDR EMIE and through the EUR grant NanoX $n^{\circ}$ ANR-17EURE-0009 in the framework of the "Programme des Investissements d'Avenir".

\section{Notes and references}

1 P. Pawlow, Z. Phys. Chem., 1909, 65, 1-35.

2 P. Buffat and J.-P. Borel, Phys. Rev. A, 1976, 13, 2287-2298.

3 R. S. Berry, Sci. Am., 1990, 263, 50-56.

4 P. Labastie and R. L. Whetten, Phys. Rev. Lett., 1990, 65, 1567-1570.

5 D. Wales, Energy Landscapes: Applications to Clusters, Biomolecules and Glasses, Cambridge University Press, 2004.

6 S. Weerasinghe and F. G. Amar, Z. Phys. D - Atoms Molec. Clusters, 1991, 20, 167-171.

7 J. D. Honeycutt and H. C. Andersen, J. Phys. Chem., 1987, 91 , 4950-4963.

8 M. Schmidt, R. Kusche, B. von Issendorff and H. Haberland, Nature, 1998, 393, 238-240.

9 G. A. Breaux, R. C. Benisrchke, T. Sugai, B. S. Kinnear and M. F. Jarrold, Phys. Rev. Lett., 2003, 91, 215508.

10 G. A. Breaux, D. A. Hillman, C. M. Neal, R. C. Benirschke and M. F. Jarrold, J. Am. Chem. Soc., 2004, 126, 8628-8629.

11 G. A. Breaux, B. Cao and M. F. Jarrold, J. Phys. Chem. B, 2005, 109, 16575-16578.

12 G. A. Breaux, C. M. Neal, B. Cao and M. F. Jarrold, Phys. Rev. Lett., 2005, 94, 173401.

13 F. Chirot, P. Feiden, S. Zamith, P. Labastie and J.-M. L'Hermite, J. Chem. Phys., 2008, 129, 164514.

14 J. Boulon, I. Braud, S. Zamith, P. Labastie and J.-M. L'Hermite, J. Chem. Phys., 2014, 140, 164305.

15 A. A. Shvartsburg and M. F. Jarrold, Phys. Rev. Lett., 2000, 85, 2530-2532.

16 B. Cao, A. K. Starace, O. H. Judd and M. F. Jarrold, J. Chem. Phys., 2009, 130, 204303.

17 A. K. Starace, C. M. Neal, B. Cao, M. F. Jarrold, A. Aguado and J. M. López, J. Chem. Phys., 2009, 131, 044307.

18 R. Poteau, F. Spiegelmann and P. Labastie, Z. Phys. D - Atoms Molec. Clusters, 1994, 30, 57-68.

19 L. J. Lewis, P. Jensen and J.-L. Barrat, Phys. Rev. B, 1997, 56, 2248-2257.

20 I. L. Garzón and J. Jellinek, Z. Phys. D - Atoms Molec. Clusters, 1991, 20, 235-238.

21 F. Calvo and J. P. K. Doye, Phys. Rev. B, 2004, 69, 125414.

22 F. Calvo and F. Spiegelman, J. Chem. Phys., 2004, 120, 96849689.

23 Manninen, K., Rytkönen, A. and Manninen, M., Eur. Phys. J. D, 2004, 29, 39-47.

24 M. Atiş, H. Aktaş and Z. B. Guvenç, Model Simul Mat Sci Eng, 2005, 13, 1411-1432.

25 H. Arslan and M. H. Guven, New J. Phys., 2005, 7, 60-60. 
26 C. Mottet, G. Rossi, F. Baletto and R. Ferrando, Phys. Rev. Lett., 2005, 95, 035501.

27 J. C. Ruiz Gómez and L. Rincón, Rev. Mex. Phys., 2007, 53, 208-211.

28 B. Soulé de Bas, M. J. Ford and M. B. Cortie, J. Phys.: Condens. Matter, 2006, 18, 55-74.

29 K. Krishnamurty, G. S. Shafai, D. G. Kanhere, B. Soulé de Bas and M. J. Ford, J. Phys. Chem. A, 2007, 111, 10769-10775.

30 E. K. Yildirim, M. Atis and Z. B. Guvenc, Phys. Scr., 2007, 75, 111-118.

31 A. Aguado and J. M. López, J. Phys. Chem. Lett., 2013, 4, 2397-2403.

32 M. Rapacioli, N. Tarrat and F. Spiegelman, J. Phys. Chem. A, 2018, 122, 4092-4098.

33 D. Schebarchov, F. Baletto and D. J. Wales, Nanoscale, 2018, 10, 2004-2016.

34 T. Castro, R. Reifenberger, E. Choi and R. P. Andres, Phys. Rev. $B, 1990,42,8548-8556$.

35 C. L. Cleveland, W. D. Luedtke and U. Landman, Phys. Rev. B, 1999, 60, 5065-5077.

36 S. Zhao, S. Wang and H. Ye, J. Physical Soc. Japan, 2001, 70, 2953-2957.

37 M. Asoro, J. Damiano and P. Ferreira, Microsc. Microanal., 2009, 15, 706-707.

38 A. Aguado and M. F. Jarrold, Annu. Rev. Phys. Chem., 2011, 62, 151-172.

39 F. Calvo and F. Spiegelmann, J. Chem. Phys., 2000, 112, 2888.

40 J. Adekoya, O. Olurotimi, T. Siyanbola, E. Dare and N. Revaprasadu, in Band Structure, Morphology, Functionality, and Size-Dependent Properties of Metal Nanoparticles, DOI: 10.5772/intechopen.72761 In book: Noble and Precious Metals - Properties, Nanoscale Effects and Applications, DOI:10.5772/intechopen.72761, 2018.

41 H. A. Alarifi, M. Atiş, C. Ozdogan, A. Hu, M. Yavuz and Y. Zhou, J Phys. Chem. C, 2013, 117, 12289-12298.

42 K. G. Steenbergen, D. Schebarchov and N. Gaston, J. Chem. Phys., 2012, 137, 144307.

43 O. A. Yeshchenko, I. M. Dmitruk, A. A. Alexeenko and A. V. Kotko, Nanotechnology, 2010, 21, 045203.

44 M. Asoro, D. Kovar, J. Damiano and P. Ferreira, Microsc. Microanal., 2010, 16, 1802-1803.

45 P. Chandrachud, K. Joshi, S. Krishnamurty and D. G. Kanhere, Pramana - J. Phys., 2009, 72, 845-855.

46 C. L. Cleveland, W. D. Luedtke and U. Landman, Phys. Rev. Lett., 1998, 81, 2036-2039.

47 M. J. Ford, B. Soulé de Bas and M. B. Cortie, Mater. Sci. Eng. $B, 2007,140,177-181$.

48 M. Van den Bossche, J. Phys. Chem. A, 2019, 123, 3038-3045.

49 Y. Wang, S. Teitel and C. Dellago, Chem. Phys. Lett., 2004, 394, $257-261$.

50 F. Baletto, J. Phys.: Condens. Matter, 2019, 31, 113001.

51 N. Tarrat, M. Rapacioli, J. Cuny, J. Morillo, J.-L. Heully and
F. Spiegelman, Comput. Theor. Chem., 2017, 1107, 102-114.

52 N. Tarrat, M. Rapacioli and F. Spiegelman, J. Chem. Phys., 2018, 148, 204308.

53 H. Häkkinen, M. Moseler and U. Landman, Phys. Rev. Lett., 2002, 89, 033401.

54 H. Häkkinen, M. Moseler, O. Kostko, N. Morgner, M. A. Hoffmann and B. v. Issendorff, Phys. Rev. Lett., 2004, 93, 093401.

55 L. Cheng, X. Zhang, B. Jin and J. Yang, Nanoscale, 2014, 6, 12440-12444.

56 I. Hamid, M. Fang and H. Duan, AIP Advances, 2015, 5, 047129.

57 D. Porezag, T. Frauenheim, T. Köhler, G. Seifert and R. Kaschner, Phys. Rev. B, 1995, 51, 12947-12957.

58 G. Seifert, D. Porezag and T. Frauenheim, Int. J. Quantum Chem., 1996, 58, 185-192.

59 M. Elstner, D. Porezag, G. Jungnickel, J. Elsner, M. Haugk, T. Frauenheim, S. Suhai and G. Seifert, Phys. Rev. B, 1998, 58, 7260-7268.

60 L. F. L. Oliveira, N. Tarrat, J. Cuny, J. Morillo, D. Lemoine, F. Spiegelman and M. Rapacioli, J. Phys. Chem. A, 2016, 120, 8469-8483.

61 J. Cuny, N. Tarrat, F. Spiegelman, A. Huguenot and M. Rapacioli, J. Phys.: Condens. Matter, 2018, 30, 303001.

62 A. Fihey, C. Hettich, J. Touzeau, F. Maurel, A. Perrier, C. Köhler, B. Aradi and T. Frauenheim, J. Comput. Chem., 2015, 36, 2075-2087.

63 B. Szűcs, Z. Hajnal, R. Scholz, S. Sanna and T. Frauenheim, Appl. Surf. Sci., 2004, 234, 173-177.

64 Y. Sugita and Y. Okamoto, Chem. Phys. Lett., 1999, 314, 141151.

65 T. Heine, M. Rapacioli, S. Patchkovskii, J. Cuny, J. Frenzel, A. Koster, P. Calaminici, H. A. Duarte, S. Escalante, R. FloresMoreno, A. Goursot, J. Reveles, D. Salahub and A. Vela, deMonNano, http://demon-nano.ups-tlse.fr/, 1st Sept 2016.

66 L. F. L. Oliveira, J. Cuny, M. Moriniere, L. Dontot, A. Simon, F. Spiegelman and M. Rapacioli, Phys. Chem. Chem. Phys., 2015, 17, 17079-17089.

67 S. Nosé, J. Chem. Phys., 1984, 81, 511.

68 W. G. Hoover, Phys. Rev. A, 1985, 31, 1695-1697.

69 F. Furche, R. Ahlrichs, P. Weis, C. Jacob, S. Gilb, T. Bierweiler and M. M. Kappes, J. Chem. Phys., 2002, 117, 6982-6990.

70 P. Gruene, D. M. Rayner, B. Redlich, A. F. G. van der Meer, J. T. Lyon, G. Meijer and A. Fielicke, Science, 2008, 321, 674-676.

71 A. Lechtken, C. Neiss, J. Stairs and D. Schooss, J. Chem. Phys., 2008, 129, 154304.

72 G. Kaye and T. Laby, Tables of physical and chemical constants, Longman, London, UK, 15th edition, 1993.

73 J. Akella and G. C. Kennedy, J. Geophys. Res., 2019, 76, 49694977.

74 K. L. Pyfer, J. O. Kafader, A. Yalamanchali and M. F. Jarrold, The Journal of Physical Chemistry A, 2014, 118, 4900-4906.

75 J. P. Rose and R. S. Berry, Z. Phys. D - Atoms Molec. Clusters, 1993, 26, 178-180. 